MSc Anđelka Štilić, Academy of Applied Studies Belgrade, The College of Tourism, andjelka@visokaturisticka.edu.rs

Mr Miloš Nicić, Academy of Applied Studies Belgrade, The College of Tourism, milos.nicic@visokaturisticka.edu.rs

DOI 10.5937/turpos0-35298

UDK 338.482:159.947.2

338.488.1:656.713

\title{
SHOULD I LOOK OR SHOULD I BOOK
}

\section{OD „SAMO GLEDAM“ DO REZERVACIJE AVIO KARTE}

\begin{abstract}
The online booking behaviour of tourist website visitors shows that there is a transition from browsing to the purchasing process. Potential travellers are expected to benefit from a broad range of market opportunities madeavailable by the Internet, the most revolutionary of which is the opportunity for price reductions as a direct result of the elimination of intermediaries in the travel industry distribution chain. Customers have to deal with a variety of challenges and limits when provided with various alternatives for even simple and low-cost travel bookings, and word-ofmouth from online reviews acts as a vital source of information for customers. $A$ significant component in influencing customer decision-making is eWOM and it is also a key factor in the individual booking of services and products. Customers' perception of the credibility of reviews significantly influences their behaviouralintentions and the role of eWOM in providing travel information and tourists' behavioural intent can produce "myths" on the opportunities for travel savings and air tickets cost.
\end{abstract}

Keywords: tourism, airfares, eWOM, booking cost savings, myths

Ključne reči: turizam, avio karte, eWOM, smanjenje troškova rezervacije, mitovi

\section{Introduction}

Today's cutting-edge in the travel sector is e-commerce. It is one of the industries where business is already being done successfully on the Internet, and where the relevance of e-commerce is expected to expand even more(Anckar et al., 2000). Online tourism booking refers to customers buying tourism products and services such as airline tickets, hotel arrangements, travel packages, etc., through tourism service providers online(Chen \& Li, 2020). According to research (Zhu, 2014) on the online booking behaviour of tourist websites ' visitors, there is a transition from browsing to purchasing. According to the studies on online tourist booking behaviour (Chen $\& \mathrm{Mu}, 2007$ ) the reasons why customers select online tourism booking were time savings, comprehensive information and low pricing.

Tourism eWOM (electronic word-ofmouth) has been studied and researched for about a decade. eWOM refers to the process of individuals passing on good and bad comments about products and services to other consumers over the Internet (Bussiere, 2015). After travel, 100 percent of internet users (Jin, 2017) tend to share their experience via online interaction and word-of-mouth from these online reviews acts as a vital information source for customers (Chevalier \&May- 
zlin, 2006). Significant component in influencing customer decision-making is eWOM and it is also a key factor in booking services and products (Chevalier \&Mayzlin, 2006; Shen et al., 2019).

Air travel is one of the most convenient means of long-distance travel at both the regional and international levels, and there are undoubtedly many airline service providers available on the global market. The tourist industry and airlines are motivated to acquire customers in a competitive environment.

For international trips in the past, the customers mostly relied on the service of travel products offered by travel agencies, but nowadays, the variety of opportunities for travel destinations, hotel reservations, and flight ticket purchases has become diversified and subdivided through social media and the Internet. The number of occasions when travel arrangements are made, airplane tickets are purchased, and hotel rooms are reserved as a result of various travel information given via social media has rapidly increased. Furthermore, information may be accessed and shared at any time or location, allowing consumers to make more informed decisions while planning international journeys (Seo et al., 2020).

\section{Should I look or should I book}

Although visiting an airline's representative office is still an option, there are alternative ways to book airline tickets without the involvement of travel agencies. Independent online reservations allow passengers to compare the prices of tickets from multiple airlines at the same time, giving them additional alternatives to select from. In terms of tourism and airline bookings, one of the most often requested customer inquiries nowadays is related to questions on how to purchase airline tickets online, and the ever-increasing worldwide effect of the Internet is demonstrating its true potential in this field. The entire online booking pro- cedure is incredibly quick, and reservations may be made from any device, such as a smartphone, tablet or laptop i.e. any device with an Internet connection.

$A$ reservation can be made using either a direct or indirect booking method. Direct channels are airline web presentations or applications that enable customers to make direct reservations with their preferred airline, and OTA (Online travel agency) booking channels, such as Kayak, Expedia, or SkyScanner, are examples of indirect booking channels. Indirect channels provide a platform where customers could compare and ultimately select among several flights from various airlines. The difference between indirect and direct channels makes a subtle difference in the reservation procedures, but the primary priority when making travel bookings on the Internet is to select a journey that satisfies the goals and needs of the customer.

Potential travellers are expected to benefit from a broad range of market opportunities made available by the Internet, the most revolutionary of which is the probability of price reductions as a direct result of the elimination of intermediaries in the travel industry distribution chain. However, there are numerous challenges to broad adoption of online purchase solutions solely. The customers may find it difficult to overcome the problem of becoming lost in cyberspace, the abundance of information, and ineffective browsing (Anckar et al., 2000).

Customers must deal with a variety of challenges and limits when provided with various alternatives for even simple and low-cost travel bookings. In the process of booking, a traveller considers several factors. These factors might include cost, travel duration, the number of stoppages, the amount of luggage permitted and previous customer comments, among others(Kumar \&Zymbler, 2019).

The Internet's information overload is a reality, as are numerous limitations when making travel reservations. This means that 
customer online reservation systems, in which the customer is in charge of preparing the trip and making the arrangements, may be far too complex for all but the most sophisticated users (Anckar et al., 2000).

\section{Easy as 1, 2, 3...?}

Finding a reasonably priced ticket could be challenging due to the frequent changes in airfare prices and the great amount of internet sites from which a ticket could be purchased from (Santos Rodríguez, 2018).
Making an instant reservation for a flight that is hours or days away can be expensive; thus, the first step in understanding how to book flights online is to plan a trip in advance.

Outline travel plans provide the idea of the travel dates, which assists in the ,hunt" for flights that correspond to the plan. Customers can also filter flights depending on the destination and take flight prices into account. Plan flexibility helps in identifying days when tickets are less expensive, and creating an outline trip plan with flexible travel dates may lead to cost savings (Figure 1).

Figure 1: Belgrade - Paris - Belgrade, flight prices overview, "magic number: 54" of advance booking (Skyscanner)

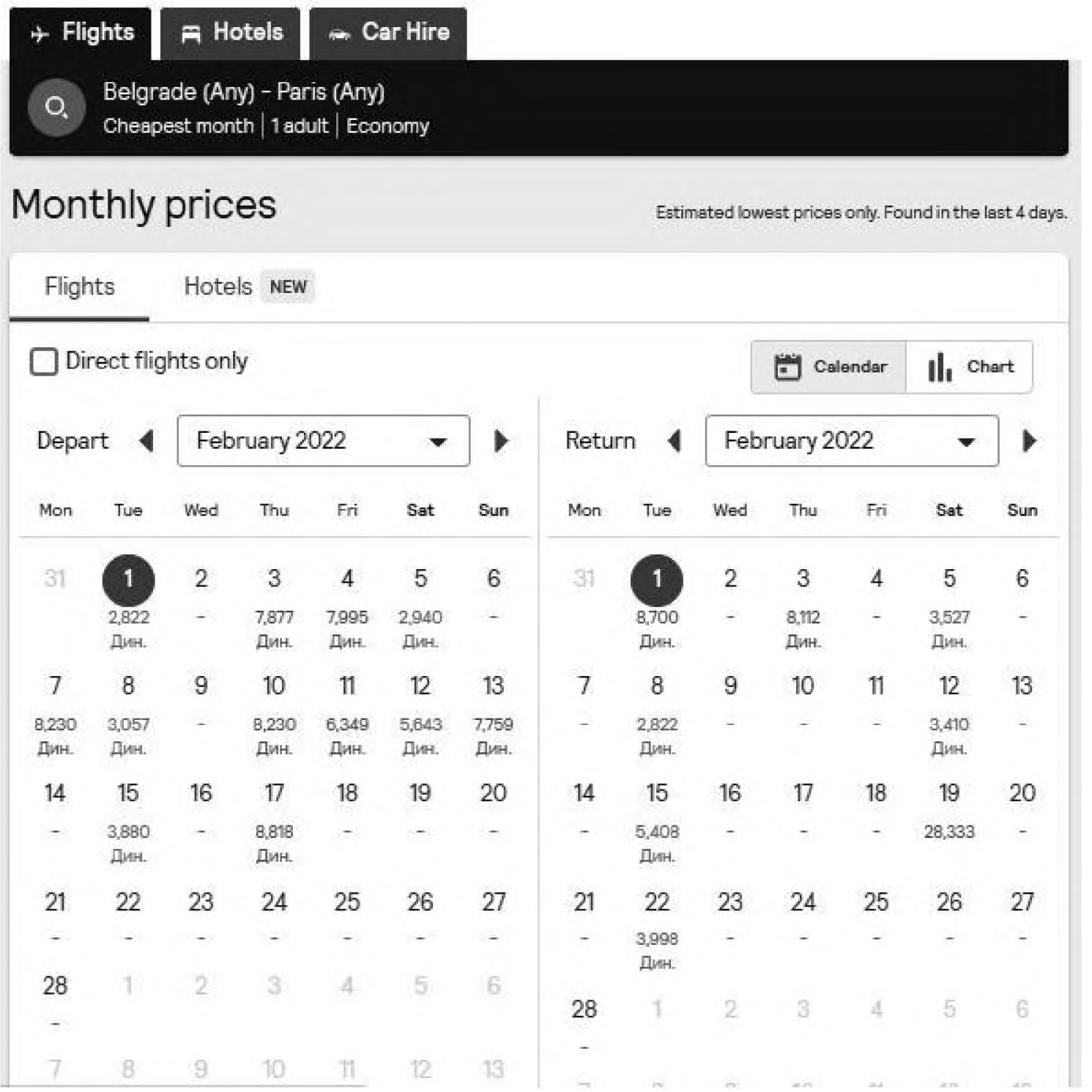

Source: Author`s research on Skyscanner.net (access date December 2021) 
Once the approximate travel dates have been decided, the next step in the online ticket booking procedure should be comparing available flights. Customers have the option of taking economical flights with low-cost carriers or a luxury air travel arrangement which will be reflected in the price.

Figure 2: Belgrade - Paris - Belgrade, flight options overview (Skyscanner)

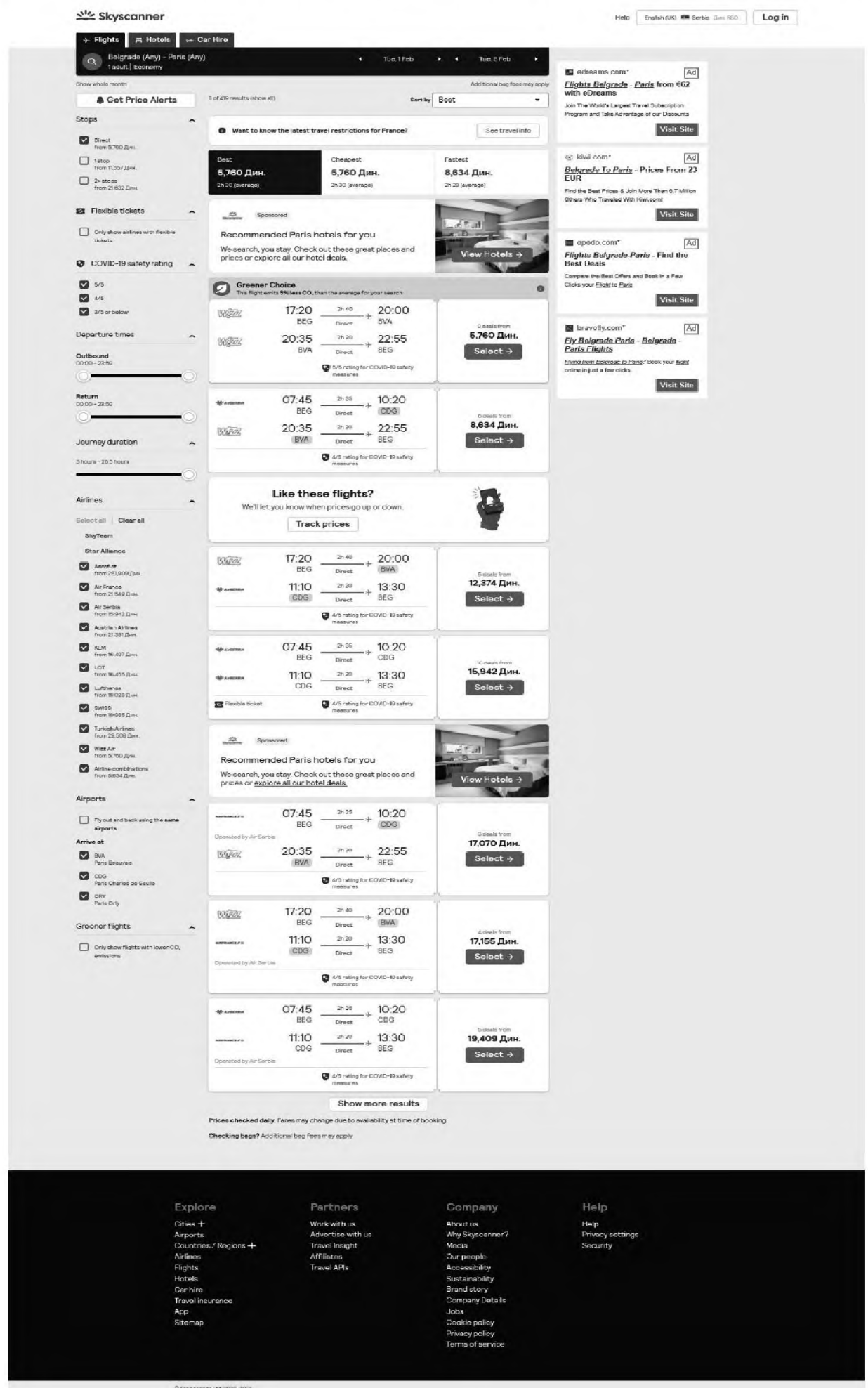

Source: Author research on Skyscanner.net (access date December 2021) 
Significant savings may be accomplished in a number of ways, whether in economy or premium class of travel, e.g.:

- Campaign ticket purchase;

- Promotional coupons for discounted ticket purchases;

- Purchase of „light" economy class rather than traditional economy class (higher restrictions, impossibility of refund in case of cancellation, only hand luggage, etc.);

- Sponsored credit cards discounts;

- Refunds for certain payment types.

\section{eWOM myths}

Customers' perception of the credibility of reviews significantly influences their behavioural intentions and the role of online resources, including eWOM, in providing travel information and tourist's behavioural intent (Nechoud, et al., 2021) produced "myths" on possibility of travel savings and air tickets cost.

Myth 1 states that there is a month in the year when tickets are the cheapest to purchase. This myth relates to the gap between the time of booking and the planned trip dates. The optimum time to buy cheaper tickets is from 21 to 121 days in advance, with 54 as a magic number (Cheapair, 2018). This myth would apply to standard travels, but not to travels planned for high-traffic days, such as Christmas, New Year, and the like. If customers book too far in advance, the available rates will almost certainly be higher, and if they decrease later, the passenger will be unable to take advantage of the reduced price without paying regular change costs, therefore eliminating the possibility of saving.

Myth 2 states that there are particular days of the week when tickets are less expensive to purchase. This myth relates to the selection of a certain day of the week for travel, regardless of whether it is a busy season or not. Flights throughout the middle of the week are less expensive, and cheaper tickets are more frequently available. It would also be „wise" to avoid periods with a high volume of transactions, such as paycheck dates.

Myth 3 states that there is a time of day when tickets are less expensive to purchase. According to this belief, tickets should be purchased on Tuesday night (after midnight). Why only on Tuesdays? According to the myth, low-cost airline tickets become available on Sunday evenings and passengers have 24 hours to purchase them after booking. At midnight on Tuesday, all discounted tickets that were not purchased after the reservation merge back into the company's systems, and it is then ,the ideal time of purchase."

Myth 4 states that a person's search history can influence the cost of available tickets. According to this myth, it is preferable to purchase tickets on a computer that has had its cookies removed or on an entirely different computer that has never looked for flights before. This myth has spread so far that in addition to the ,fact" that airlines monitor your internet conduct, and perhaps your IP address, frequent search on specific tickets (and dates) increase the price of air fare.

Given the eWOM's immense power (Nechoud, et al., 2021), even the "myths" should not be disregarded, but rather utilized to enhance the effectiveness of marketing approaches in the travel industries.

\section{Conclusion}

Several studies have examined the factors that impact airline service quality, such as the quality of airline websites, airline brand positioning, and the elements that make up airline service quality, as well as the passenger expectations. The vast majority of studies have concentrated on the relationship between airline service qualities and overall service quality and/or satisfac- 
tion. The whole service quality and/or satisfaction of airlines grows when service characteristics perform well (Park et al., 2020).

Unlike other industries, the airline industry's products are seats and services, which are both material and intangible as entire services. Even if products are not sold, they have a distinct feature where a certain amount of money is spent, thus it is critical to attract potential customers through various marketing activities and, in the long run, enhance brand values (Seo et al., 2020).

Despite the catastrophic downturn in air travel caused by the COVID19 pandemic, the travel industry's push toward airline retailing accelerated in 2020 and continued in 2021 (IATA, 2021) and customers are looking for travel information everywhere. There is a great deal of information available online, but which one is more reliable and trustworthy? To allow the customer to accept and believe the source from which it is coming, the resource must be credible. With the influence of eWOM, significant effort must be made to reduce and utilize dissatisfied clients (Ahmad et al., 2020), as eWOM adoption impacts decision making on purchase behaviour of customers (Tien, 2019).

If a customer has a particular itinerary in mind, he/she must be ready to purchase when a good fare is offered as airfares are subject to change quickly. It is risky to let it go away as one ,is thinking about it". While considering options, other customers are keeping an eye on prices as well, and someone else is likely to take advantage of a low fare. It is vital to make a decisionfast (Cheapair, 2018)as, in the end, customers are evaluating the order of two basic states of prices: whether it satisfies or does not satisfy (Štilić, 2019) their idea or what they intend to pay for airfare.

\section{Reference}

Ahmad, A., Abuhashesh, M., Obeidat, Z., \&AlKhatib, M. (2020). E-WOM and airline e-ticket purchasing intention: Mediating effect of online passenger trust. Management Science Letters, 10(12), 2729-2740.

Anckar, B., Olofsson, S., \& Walden, P. (2000). Agents as Agents: A Virtual Assistant for Self-bookings in Travel.

Bussiere, D.E. (2015) Evidence and Implications of Electronic Word-of-Mouth. Proceedings of the 2000 Academy of Marketing Science (AMS) Annual Conference. Developments in Marketing Science, 5, 361.

Cheapair. (2018). 2018 Airfare Study - The Best Time to Buy Flights, Based on 917 Million Airfares [Online]. Available: cheapair.com/blog/the-best-time-tobuy-flights-based-on-917-million-airfares/

Chen, H.P. and Mu, H.L. (2007) Study on Online Travel Booking Market and B to $\mathrm{C}$ e-Commerce Model. Scientific and Technological Information, 7, 88-89.

Chen, X., \& Li, Z. (2020). Research on the Behavior of College Students' Online Tourism Booking Based on TAM. Journal of Service Science and Management, 13(01), 28-44.

Chevalier, J. and Mayzlin, D. (2006) The Effect of Word of Mouth on Sales: Online Book Reviews. Journal of Marketing Research, 43, 345-354.

IATA Annual Review. (2021). https:// www.iata.org/contentassets/c81222d96c9a4e0bb4ff6ced0126f0bb/iata-annual-review-2021.pdf

Jin, Z.X. (2017) Data Analysis of Online Travel Users in the Context of "Internet Plus". Market Modernization, 19, 54-55 
Kumar, S., Zymbler, M. A machine learning approach to analyze customer satisfaction from airline tweets. J Big Data 6, 62 (2019).

Nechoud, L., Ghidouche, F., \&Seraphin, H. (2021). The influence of eWOM credibility on visit intention: An integrative moderated mediation model. Journal of Tourism, Heritage \& Services Marketing (JTHSM), 7(1), 54-63.

Nechoud, L., Ghidouche, F., \&Seraphin, H. (2021). The influence of eWOM credibility on visit intention: An integrative moderated mediation model. Journal of Tourism, Heritage \& Services Marketing (JTHSM), 7(1), 54-63.

Park, S., Lee, J. S., \&Nicolau, J. L. (2020). Understanding the dynamics of the quality of airline service attributes: Satisfiers and dissatisfiers. Tourism Management, 81, 104163.

Santos Rodríguez, G. (2018). The change in airfare tickets based on the weekday and the continent. Computer Science.
Seo, E. J., Park, J. W., \& Choi, Y. J. (2020). The Effect of Social Media Usage Characteristics on e-WOM, Trust, and Brand Equity: Focusing on Users of Airline Social Media. Sustainability, 12(4), 1691.

Shen, H., Zhao, J. and Hu, F.L. (2019) The Influence of E-Word-of-Mouth on Online Purchase Decision. Tourism Forum, 1-11.

Štilić, A. (2019). CRITERIAS AS ELEMENTS OF THE MULTI CRITERIA ANALYSIS IN SELECTION OF PERSONNEL IN THE TOURISM INDUSTRY. Knowledge International Journal, 32(1), 51-54.

Tien, D. H., Rivas, A. A. A., \& Liao, Y. K. (2019). Examining the influence of customer-to-customer electronic word-ofmouth on purchase intention in social networking sites. Asia Pacific Management Review, 24(3), 238-249.

Zhu, J.Y. (2014). The Analysis of Online Booking Behavior of Travel Websites' User. Master's Dissertation, East China Normal University, Shanghai. 